\title{
Telaah Kritis Nilai-nilai Kebudayaan Islam "Studi Kasus Tradisi Ramadhan \& Idul Fitri di Desa Pageraji Kabupaten Banyumas"
}

\author{
Fatoni Achmad \& Faiq Fauziya Putri \\ Universitas Negeri Jenderal Soedirman Purwokerto
}

\begin{abstract}
In doing good deeds, each region in the world has its own characteristics. The custom then experienced a mix with Islamic traditions which ultimately created a harmony without leaving the applicable Shari'a. Acculturation of local culture with Islamic culture also occurred in Pageraji Village, Cilongok District, Banyumas Regency, Central Java. The Pageraji village community has a number of customs related to Islam that are still enduring today. The tradition is that the tarawih prayer time is slightly different from other regions, which is between 22:00 - 23:00, and the tradition of eating together and grave pilgrimage after the Eid prayer.
\end{abstract}

Keywords: Value, Tradition, Islam, Ramadhan, Eid al-Fitr

\section{PENDAHULUAN}

Ramadhan merupakan salah satu bulan dalam sistem penanggalan Hijriyah. Dalam bulan ramadhan, umat muslim diwajibkan berpuasa satu bulan penuh. Bulan ramadhan selalu dinantikan umat muslim karena bulan tersebut penuh dengan rahmat dan berkah. Umat muslim diseluruh dunia berlomba-lomba dalam beribadah dan beramal kebaikan.

Dalam melakukan amal kebaikan, setiap daerah di dunia memiliki ciri khas masing-masing. Seperti yang kita ketahui bahwa setiap tempat mempunyai tradisi atau kebiasaan masing-masing. Kebiasaan tersebut 
kemudian mengalami perpaduan dengan tradisi Islam yang pada akhirnya menciptakan sebuah harmoni tanpa keluar dari syariat yang berlaku.

Akulturasi budaya lokal dengan budaya Islam pun terjadi di Desa Pageraji, Kecamatan Cilongok, Kabupaten Banyumas, Jawa Tengah. Masyarakat Desa Pageraji memiliki beberapa kebiasaan yang berkaitan dengan Islam. Kebiasaan ini tentunya menyangkut kemaslahatan umat sehingga menciptakan masyarakat yang rukun.

Seiring berkembangnya zaman, dimana nilai-nilai individualisme lebih menonjol, tradisi atau kebiasaan yang menyangkut masyarakat secara umum mulai memudar. Meskipun begitu, masih ada beberapa tradisi yang masih di bertahan sampai saat ini.

\section{PEMBAHASAN}

\section{A. Deskripsi Umum tentang Ramadhan dan Idul Fitri}

Puasa merupakan salah satu ibadah pokok yang termasuk dalam lima rukun Islam. Puasa menurut bahasa dapat bermakna sebagai menahan atau berdiam. Menurut istilah, puasa dapat diartikan dengan menahan diri dari makan, minum dan berhubungan seksual mulai dari terbit fajar sampai terbenamnya matahari dengan syarat-syarat yang ditentukan. ${ }^{1}$

Ramadhan merupakan salah satu bulan dalam sistem penanggalan Hijriyah. Bulan Ramadhan merupakan bulan dimana Al-Qur'an diturunkan. Pada bulan Ramadhan, umat muslim diwajibkan berpuasa satu bulan penuh. Puasa pada bulan Ramadhan hukumnya wajib 'ain, artinya kewajiban yang dibebankan kepada setiap orang yang sudah balig berakal (mukalaf), tanpa terkecuali. ${ }^{2}$

Bulan Ramadhan sangat dinantikan umat muslim karena bulan ramadhan merupakan bulan penuh berkah. Selain menjalankan kewajiban

\footnotetext{
${ }^{1}$ Syarifuddin Amir, Garis-Garis Besar Fiqh. (Bogor: Kencana, 2003), hlm 53.

${ }^{2}$ Satria Efendi, Ushul Fiqh, (Jakarta: Prenada Media, 2005), hlm 44.
} 
puasa, umat muslim berlomba-lomba dalam ibadah lainnya untuk mendapatkan pahala yang berlipat.

Dalam Al-Qur'an banyak dijelaskan mengenai kewajiban berpuasa pada bulan Ramadhan. Salah satunya dalam surat Al-Baqarah ayat 185:

Artinya: Bulan Ramadhan adalah (bulan) yang di dalamnya diturunkan alQur'an, sebagai petunjuk bagi manusia dan penjelas-penjelasan mengenai petunjuk itu, dan pembeda (antara yang benar dan yang bathil). Karena itu, siapa diantara kamu ada di bulan itu, maka berpuasalah. Dan siapa sakit atau dalam perjalanan (dia tidak berpuasa), maka (wajib menggantinya), sebanyak hari yang ditinggalkannya itu pada hari-hari yang lain. Allah menghendaki kemudahan bagimu, dan tidak menghendaki kesukaran bagimu. Hendaklah kamu mencukupkan bilangannya dan mengagungkan Allah atas petunjuk-Nya yang diberikan kepadamu, agar kamu bersyukur. ${ }^{3}$

Dalam menjalankan puasa ada beberapa hal urgen yang perlu diperhatikan yaitu rukun puasa, beberapa rukun puasa tersebut adalah sebagai berikut :

1. Niat

Niat merupakan rukun pertama yang harus dilaksanakan karena berkaitan dengan sah dan tidaknya suatu amalan yang sedang dikerjakan serta guna mengetahui maksud dan tujuan dari amalan tersebut (Lillahi Ta'ala). Niat puasa bisa dilakukan dengan cara mengucapkan dengan lisan dan membenarkan dalam hati serta melaksanakan dengan perbutannya. Penetapan niat dalam puasa ramadhan berbeda dengan puasa sunnah lainya, karena niat puasa ramadhan dilakukan pada saat sebelum menjalankan ibadah suci ramadhan atau tepatnya pada malam hari sebelum terbitnya fajar. Sedangkan niat puasa sunnah lainnya dapat ditetapkan sebelum dhuhur.

${ }^{3}$ Ahmad Hatta, Tafsir Qur'an Per Kata; Dilengkapi Dengan Asbabun Nuzul \& Terjemahan, (Jakarta: Maghfirah Pustaka, 2009), hlm 28.

Lembaga Penelitian dan Pengabdian Kepada Masyarakat (LPPM) Sekolah Tinggi Islam Blambangan (STIB) Banyuwangi 


\section{Menahan Diri}

Menahan diri disini maksudnya adalah menahan dari segala sesuatu yang dapat membatalkan puasa mulai dari terbitnya fajar sampai terbenamnya matahari termasuk di antaranya makan, minum dan bergaul dengan istri atau suami bagi yang sudah menikah $^{4}$ serta lebih jauh lagi menahan diri dari segala yang dilarang oleh Allah dan menjalankan apa yang telah disyari'atkan. Hal ini sesuai dengan firman Allah dalam surat Al Baqarah ayat 187:

Artinya: "Dihalalkan bagi kamu pada malam hari bulan puasa bercampur dengan isteri-isteri kamu; mereka adalah pakaian bagimu, dan kamupun adalah pakaian bagi mereka. Allah mengetahui bahwasanya kamu tidak dapat menahan nafsumu, karena itu Allah mengampuni kamu dan memberi maaf kepadamu. Maka sekarang campurilah mereka dan ikutilah apa yang telah ditetapkan Allah untukmu, dan makan minumlah hingga terang bagimu benang putih dari benang hitam, yaitu fajar. Kemudian sempurnakanlah puasa itu sampai (datang) malam, (tetapi) janganlah kamu campuri mereka itu, sedang kamu beri'tikaf dalam mesjid. Itulah larangan Allah, maka janganlah kamu mendekatinya. Demikianlah Allah menerangkan ayat-ayat-Nya kepada manusia, supaya mereka bertakwa".

Apabila seorang muslim percaya bahwa Al-Qur'an adalah firman Allah, maka segala isi Al-Qur'an yang brisi perintah seperti yag terdapat dalam surat Al-Baqarah ayat 183, dan diiringi pula dengan Hadist Nabi yang menyatakan bahwa puasa adalah salah satu rukun Islam, seperti hadis terdahulu, maka tidak ada alasan bagi orang Muslim untuk tidak berpuasa di bulan Ramadhan Larangan utama dalam berpuasa adalah makan, minum, dan hubungan kelamin mulai dari terbit fajar sampai terbenam matahari. $^{6}$

\footnotetext{
${ }^{4}$ Muhamad Bagir Al-Habsyi, Fiqih Praktis. (Bandung: Mizan, 2000), hlm. 346.

${ }^{5}$ https://tafsirweb.com/697-surat-al-baqarah-ayat-187.html

${ }^{6}$ Zakiah Daradjad, Puasa, (Bandung: CV Ruhama, 1996), hlm. 13.
} 
Dari beberapa rukun puasa di atas ada beberapa syarat wajib yang mesti diperhatikan bagi seorang muslim, di antaranya :

1. Islam

2. Baligh

3. Berakal

4. Suci dari haid dan nifas (Perempuan)

5. Tidak musafir (dalam perjalanan : ketentuan berlaku )

6. Tidak sakit (dapat melaksanakan puasa) ${ }^{7}$

Sedangkan dibawah ini beberapa kondisi seseorang yang tidak diwajibkan berpuasa, yaitu :

1. Non Muslim

2. Gila

3. Anak Kecil

4. Sedang sakit

5. Musafir

6. Hamil dan menyusui ${ }^{8}$

Para ulama' telah sepakat terkait tentang syarat seseorang muslim yang diwajibkan untuk menjalankan ibadah puasa ramadhan syarat tersebut yaitu seorang muslim harus dalam keadaan baligh, berakal, sehat dan mukim. Dan bagi perempuan diharuskan dalam keadaan suci (haid \& nifas), maka tidaklah diwajibkan bagi mereka yang statusnya non muslim, mengingat puasa ramadhan merupakan ibadah yang bersifat islami serta kewajiban berpuasa tidak berlaku bagi anak-anak (anak-anak yang berpuasa hanya sebagai latihan) dan orang gila, ${ }^{9}$ hal sesuai dengan hadis Nabi yang artinya : "Ketetapan hukum tidak diberlakukan atas tiga orang;yaitu orang gila sampai ia sadar kembali (yakni dari sebuah hlm. 67.

${ }^{7}$ Hasbi Ash Shiddieqy, Pedoman Puasa, (Jakarta: NV Bulan Bintang, 1993).

${ }^{8}$ Hasbi Ash Shiddieqy, Pedoman.... hlm. 67.

${ }^{9}$ Muhamad Bagir Al-Habsyi, Fiqih Praktis.(Bandung: Mizan, 2000) hlm. 347.

Lembaga Penelitian dan Pengabdian Kepada Masyarakat (LPPM) Sekolah Tinggi Islam Blambangan (STIB) Banyuwangi 
kegilaan), orang yang dalam keadaan tidur sampai ia terjaga, dan anak kecil sampai ia baligh".(HR Ahmad, Abu Daud At-Tirmidzi).

Hakikat puasa adalah untuk mengajarkan manusia dalam menahan diri atau menahan hawa nafsu dan bersyukur. Umat muslim harus dapat bersyukur dan menghargai setiap nikmat yang telah diberikan oleh Allah SWT. Melalui puasa, umat muslim dituntut untuk menahan diri dari kenikmatan yang biasa diterima sehari-hari, seperti makan dan tidur. Dalam arti luas, hakikat puasa adalah sebagai pembelajaran bagi umat muslim untuk merasakan sesama saudara muslim yang kurang mampu, yang mungkin tidak dapat makan secara teratur sehari-harinya.

Pembelajaran tersebut erat kaitannya dengan kewajiban zakat fitrah dalam bulan Ramadhan. Pemberian zakat fitrah untuk orang-orang yang kurang mampu bertujuan agar umat muslim yang kurang mampu tersebut dapat merasakan nikmat dan mendapatkan makanan yang cukup di bulan Ramadhan dan saat hari raya Idul Fitri. Dalam hal ini pemberi zakat dapat belajar bersyukur dan melatih diri bahwa sebagian rezeki yang kita terima terdapat hak-hak orang lain didalamnya.

Idul fitri merupakan hari raya bagi umat Islam diseluruh dunia yang jatuh pada tanggal satu syawal pada kalender Hijriyah. Dalam menentukan 1 syawal dapat digunakan beberapa metode di antaranya dengan hisab, melihat hilal dan penggabungan keduanya, maka tidak jarang dijumpai perbedaan dalam penetapan awal bulan syawal, hal ini dikarenakan metode yang digunakan oleh para ulama' cenderung berbeda-beda. Selain itu, karena penentuan 1 syawal berdasarkan pada peredaran bulan setiap tahunnya, maka idul fitri akan jatuh pada tanggal yang berbeda-beda setiap tahun jika menggunakan kalender Masehi.

Secara bahasa kata idul firi terdiri dari dua kata yaitu, idul yang artinya kembali dan fitrah yang artinya suci, dengan demikian idul fitri berarti kembali firah setelah melaksaksanakan syari'at yang diperintahkan

\section{Lembaga Penelitian dan Pengabdian Kepada Masyarakat (LPPM) Sekolah Tinggi Islam Blambangan (STIB) Banyuwangi}


oleh Allah SWT yaitu puasa, dengan segala keikhlasan dan mengharap ridlo Allah semata serta menjaga diri mulai dari terbitnya fajar (makan, minum, bergaul, nafsu) sampai dengan terbenamnya matahari (magrib). Sederhananya orang yang merayakan idul fitri adalah seorang yang telah berhasil dalam pencapaiannya menempuh ujian dalam hal ini puasa dan ditutup dengan membayar zakat guna mencapai derajat muttaqin, yaitu orang yang bertaqwa. Dengan demikian kiranya sebagai manusia yang fitri hendaknya mampu menghadirkan makna dari di syari'atkanya puasa oleh Allah SWT.

\section{B. Fenomena Kebudayaan Ramadhan \& Idul Fitri Di Desa Pageraji}

Berbagai wilayah di Indonesia bahkan dunia, pasti memiliki tradisi lokal yang berbeda. Setelah Islam masuk, tentunya tradisi Islam akan berakulturasi dengan budaya lokal. Hal ini menciptakan tradisi baru dan tentunya berbeda antar wilayahnya. Meskipun berbeda dan sudah berakulturasi dengan budaya lokal, selama tidak bertentangan dengan syariat Islam maka budaya atau tradisi tersebut tidak menjadi masalah.

Pada waktu lampau, keberadaan Islam di Indonesia masih terbilang sedikit. Sekitar tahun 1960-1980 penggunaan hijab atau kerudung masih dianggap tabu oleh masyarakat. Meskipun begitu, masyarakat muslim tetap menjalankan ibadah dengan baik.

Menurut wawancara yang dilakukan dengan salah satu perangkat Desa Pageraji, yaitu Bapak Miftahul Jannah, suasana Ramadhan di waktu lampau sangat mencerminkan Islam sebagai rahmatan lil 'alamin. Suasana guyub dan hangat tercipta saat bulan Ramadhan.

Zaman dulu, kecenderungan kebiasaan Islam dipengaruhi oleh tokoh alim ulama setempat, karena adat kebiasaan jawa masih sangat kental pada saat itu. Di Desa Pageraji zaman dulu terbagi menjadi beberapa kelompok muslim karena terdapat beberapa tokoh alim ulama yang menjadi panutan saat itu. Salah satunya ada kelompok Islam aboge.

\section{Lembaga Penelitian dan Pengabdian Kepada Masyarakat (LPPM) Sekolah Tinggi Islam Blambangan (STIB) Banyuwangi}


Islam aboge saat itu mempunyai hitungan tersendiri untuk menentukan awal Ramadhan dan seringkali terjadi perbedaan dengan kelompok Islam lainnya. Salah satu tokoh alim ulama yang terkenal pada saat itu adalah R. Abu 'Umar. Dalam menentukan awal Ramadhan atau awal bulan Syawal, beliau akan memanjat pohon kelapa untuk melihat bulan, tentunya dengan beberapa tirakat yang sudah beliau lakukan.

Yang menjadi unik dari kebiasaan di bulan Ramadhan zaman dulu di Desa Pageraji adalah kelompok Islam Aboge ini dalam melaksanakan sholat tarawihnya yaitu sekitar pukul 22.00 WIB atau 23.00 WIB dan kemudian setelah sholat tarawih selesai, orang-orang biasanya melanjutkan dengan berdzikir di masjid sampai menjelang waktu sahur dan memukul bedug untuk membangunkan orang untuk sahur. Banyak pula masyarakat yang tidur di masjid sampai subuh menjelang, biasanya mereka sudah membawa bekal sahur, atau ada orang-orang yang mengirim makanan ke masjid.

Kebiasaan lainnya yang dilakukan oleh masyarakat Desa Pageraji adalah gotong royong membersihkan tempat pemakaman umum seminggu sebelum bulan Ramadhan datang dan beberapa hari sebelum hari raya Idul Fitri. Tidak hanya tempat pemakaman umum saja yang dibersihkan, akan tetapi masyarakat Desa Pageraji juga membersihkan jalan-jalan menuju masjid atau mushola. Hal ini bertujuan agar nilai-nilai kerukunan dapat terbentuk dalam masyarakat khususnya Desa Pageraji. Selain itu, masyarakat memahami bahwa kebersihan merupakan tuntunan yang disyariatkan oleh agama. Seperti yang kita ketahui, bahwa Islam sangat mencintai kebersihan.

Puasa di bulan Ramadhan yang hakikatnya agar para muslim merasakan kehidupan saudaranya yang kelaparan atau hanya dapat makan sehari sekali harus diserapi dan diterapkan dala kehidupan. Masyarakat di Desa Pageraji pada waktu dulu sangat menghargai atau meresapi hakikat

\section{Lembaga Penelitian dan Pengabdian Kepada Masyarakat (LPPM) Sekolah Tinggi Islam Blambangan (STIB) Banyuwangi}


ini. Terbukti ketika malam hari raya Idul Fitri tiba sampai setelah subuh pada 1 Syawal, masyarakat muslim di Desa Pageraji sibuk memberikan zakat kepada orang-orang yang kurang mampu dan berhak mendapatkannya. Selain itu, sebagian masyarakat yang dikenal berkecukupan atau mempunyai kelebihan makanan, pada malam hari raya Idul Fitri sibuk memasak yang nantinya masakan tersebut akan dibawa esok hari saat hari raya Idul Fitri ke masjid.

Di sinilah hakikat puasa benar-benar diterapkan masyarakat Desa Pageraji. Orang-orang yang berkecukupan akan memasak dan membawanya ke masjid saat sholat Idul Fitri. Setelah sholat Idul Fitri dan kegiatan bersalam-salaman selesai, masyarakat yang datang ke masjid akan menyantap makanan bersama-sama. Nilai saling membantu dan berbagi sangat kental terlihat dari kegiatan ini. Masyarakat yang mampu dapat bersedekah atas rezeki yang mereka peroleh, dan masyarakat yang kurang mampu dapat turut merasakan nikmat yang mungkin jarang mereka peroleh sehari-hari. Suasana dibuat senyaman mungkin tanpa pamrih untuk menghilangkan rasa canggung antara orang yang mampu dan kurang mampu. Setelah makan-makan selesai, orang-orang langsung menuju tempat pemakaman umum untuk berziarah. Tradisi ziarah kubur sangat kental di Desa Pageraji. Berikut adalah beberapa dalil tentang ziarah kubur.

Rasululloh SAW bersabda: Dahulu aku telah melarang kalian berziarah ke kubur. Namun sekarang, berziarahlah kalian ke sana. (HR. Muslim) ${ }^{10}$.

Setelah selesai ziarah, barulah masing-masing pulang ke rumah dan melanjutkan acara silaturahmi ke tetangga maupun saudara setelah dhuhur.

Setelah R. Abu 'Umar wafat, ada beberapa kebiasaan yang berubah. Sholat tarawih tidak lagi dilakukan pada pukul 23.00 WIB tetapi pukul 20.00 WIB. Namun tradisi makan bersama setelah sholat Idul Fitri tidak

${ }^{10}$ Ngabdurrohman Al-Jawi, Manan, A.G.A., Tradisi Amaliah NU \& DalilDalilnya (Jakarta: LTM-PBNU, 2011), hlm 39.

Lembaga Penelitian dan Pengabdian Kepada Masyarakat (LPPM) Sekolah Tinggi Islam Blambangan (STIB) Banyuwangi 
ditinggalkan. Begitulah bukti kepengaruhan tokoh alim ulama dalam menciptakan masyarakat dan kebiasaan Islam.

Di masa yang serba modern ini dengan kehidupan individualisme yang tinggi, berpengaruh terhadap interaksi antar masyarakat. Nilai-nilai kebersamaan dan gotong royong semakin memudar. Hal ini juga terjadi pada masyarakat Desa Pageraji, termasuk berpengaruh pada tradisi atau kebiasaan saat Ramadhan.

Pengaruh alim ulama tidak lagi seperti zaman dulu. Masyarakat lebih bersifat umum. Masyarakat mengikuti keputusan pemerintah maupun organisasi kemasyarakatan yang dia ikuti. Hal ini terlihat dari penentuan awal Ramadhan maupun 1 Syawal. Masyarakat Desa Pageraji yang notabene mengikuti Nahdlatul Ulama akan menunggu keputusan pemerintah.

Semenjak pemerintah memegang peranan penting untuk kepentingan umum dan perkembangan zaman, beberapa kebiasaan Ramadhan dan Idul Fitri di Desa Pageraji mulai berubah. Kegiatan makan bersama antar masyarakat yang mampu dan kurang mampu setiap hari raya Idul Fitri sudah tidak ada. Hal ini mulai terjadi setelah masyarakat mulai maju dan banyak masyarakat yang mampu. Tidak seperti zaman dulu dimana orang-orang yang mampu hanya sedikit dan dari kalangan tertentu saja. Walaupun seperti itu, di zaman sekarang sebenarnya masih banyak orang-orang yang kurang mampu dan membutuhkan bantuan. Akan tetapi, untuk diadakan makan bersama setelah sholat Idul Fitri di masa sekarang dinilai kurang sesuai dan masyarakat lebih memilih memberikan bantuan kepada orang-orang yang kurang mampu secara langsung.

Hilangnya tradisi makan bersama setelah sholat Idul Fitri sangat disayangkan. Dari kegiatan ini, masyarakat dapat saling merangkul, membantu dan menanamkan hakikat puasa Ramadhan. Untuk masa sekarang, mungkin masyarakat muslim hanya melaksakan ibadah puasa

\section{Lembaga Penelitian dan Pengabdian Kepada Masyarakat (LPPM) Sekolah Tinggi Islam Blambangan (STIB) Banyuwangi}


Ramadhan untuk menggugurkan kewajiban semata tanpa menghayati dan menerapkan esensi puasa Ramadhan untuk kehidupan bermasyarakat.

Tradisi yang masih dilaksanakan sampai sekarang adalah kebiasaan membersihkan makam, membesihkan jalan menuju masjid dan kebiasaan ziarah kubur setelah sholat Idul Fitri. Untuk membersihkan tempat pemakaman dan jalan menuju masjid masih dilakukan dengan gotongroyong masyarakat sekitar. Nilai-nilai kebersamaan masih terjaga dalam kegiatan ini.

Tradisi ziarah kubur juga masih terjaga sampai saat ini. Setelah sholat Idul Fitri, masyarakat akan bersalam-salaman di halaman masjid. Setelah itu, masyarakat akan pulang ke rumah masing-masing, baru setelah itu dilanjutkan ziarah kubur. Selanjutnya, masyarakat akan bersilaturahmi ke tetangga dan keluarga.

\section{SIMPULAN}

Setiap daerah di dunia memiliki tradisi atau kebiasaan yang berbeda. Kebiasaan ini kemudian berakulturasi dengan tradisi Islam membentuk tradisi baru.

Tradisi semacam ini juga terdapat di Desa Pageraji, Kecamatan Cilongok, Kabupaten Banyumas, yaitu tradisi saat bulan Ramadhan dan hari raya Idul Fitri. Tradisi itu adalah waktu pelaksaan sholat tarawih yang sedikit berbeda dengan daerah lain, dan tradisi makan bersama setelah solat Idul Fitri. Meskipun beberapa tradisi sudah hilang tergeser zaman, namun masih ada beberapa tradisi lain yang tetap melekat dalam kehidupan masyarakat Desa Pageraji.

Tradisi Islam yang berakulturasi dengan tradisi lokal sangat banyak. Selama tidak bertentangan dengan syariat Islam dan mengandung banyak kebermanfaatan, maka hal ini tidak perlu dipermasalahkan justru 
sebaliknya perlu adanya pelestarian agar kebudayaan tersebut tidak menjadi hilang.

\section{Daftar Pustaka}

Ahmad Hatta, Tafsir Qur'an Per Kata; Dilengkapi Dengan Asbabun Nuzul \& Terjemahan, Jakarta: Maghfirah Pustaka, 2009.

Hasbi Ash Shiddieqy, Pedoman Puasa, Jakarta: NV Bulan Bintang, 1993. Muhamad Bagir Al-Habsyi, Fiqih Praktis. Bandung: Mizan, 2000.

Ngabdurrohman Al-Jawi, Manan, A.G.A., Tradisi Amaliah NU \& DalilDalilnya, Jakarta: LTM-PBNU, 2011.

Satria Efendi, Ushul Fiqh, Jakarta: Prenada Media, 2005.

Syarifuddin Amir, Garis-Garis Besar Fiqh. Bogor: Kencana, 2003.

Syekh Abu Syuja' bin Husain Ahmad, Ringkasan Fikih Islam. Terj. A. Ma'ruf Asrori. Surabaya: Al-Miftah, 2000.

Zakiah Daradjad, Puasa, Bandung: CV Ruhama, 1996.

Website :

https://tafsirweb.com/697-surat-al-baqarah-ayat-187.html 